\title{
THE DIGITAL RENAISSANCE FROM DA VINCI TO TURING
}

\author{
Tula Giannini \\ School of Information \\ Pratt Institute \\ New York, USA \\ giannini@pratt.edu
}

\author{
Jonathan P. Bowen \\ School of Engineering \\ London South Bank University \\ London, UK \\ jonathan.bowen@1sbu.ac.uk
}

\begin{abstract}
The Italian Renaissance started a rebirth of culture and knowledge not experienced since Roman times. Leonardo da Vinci was arguably the leading polymath of the era. We are now in the throes of a Digital Renaissance, arguably started by Alan Turing in England. This paper draws some parallels between these two periods and speculates on the future of digital developments, especially in the context of the EVA Florence conference in Italy and the EVA London conference in the UK.
\end{abstract}

\section{INTRODUCTION}

Now in the third decade of the $21^{\text {st }}$ century, we are witnessing the merger of two revolutions across digital time and space - that of Italian Renaissance of Leonardo da Vinci's (1452-1519) [50] world with the digital revolution of Alan Turing's (1912-1954) [16] world as we enter a new "Digital Renaissance" where digital and human states of being are morphing into a new postdigital era. As the Turing Test [34] predicted, human and artificial intelligence would work side by side to advance science, art and technology as it replaces old hierarchies of society with new ways of thinking, an outcome intrinsic to the global digital ecosystem of everyday life. Owing to this, for the first time, we all have access to Leonardo da Vinci's works on the web (for example, see [46]) where they reside and interact with the art world. New fields of research such as the digital humanities and digital art history have developed in response to the wealth of digitised and born-digital material on the Internet, ripe for discovery and new contemporary interpretations, as fresh perspectives on art and life flow from digital culture.

From the vantage point of digital life, we look back 500 years to the death of Leonardo da Vinci in 1519, and are now able to study the full range of his genius through a digital lens and experience his codices and art works enhanced by the emerging technologies of VR, AR, and MR. Juxtaposing this body of work with that of Alan Turing focusing on the Turing Digital Archive [39] and publications online, brings into public view an exciting meeting of the minds between the great Italian Renaissance master [50] and the father of computer science [6]. Concentrating on their late period work, for da Vinci, 1512 to 1519, and for Turing 1948-1954, this paper illuminates their shared vision of art and science, and how they were driven by their fixation on the natural world and the complex processes that create life, real and artificial.

Turing's groundbreaking work during the last years of his life, documented in the Turing Digital Archive [39], concern his studies on artificial intelligence and machine thinking and learning [34], neural networks and finally, morphogenesis [37] including cell structure, patterns in nature, flowers and seeds, areas of study that we see strongly represented in da Vinci's drawings, such as those depicting the human foetus in the womb, flowers, plants, patterns, and the human brain. Finding disciplinary coherence, their work encompasses the fields of mathematics, geometry, embryology and engineering, areas of study that both men sought to advance, and by so doing, have deepened our understanding and appreciation of human 
consciousness and identity. Given the magnitude and impact of their work, we are awed by da Vinci's scientific discoveries and the life he breathed into his beyond-human paintings, which is matched by the brilliance of Turing's discoveries around thinking machines, AI and machine learning - making artificial life seem all too real.

Through digital research online, we see new relationships and connections between da Vinci and Turing. Travelling on a digital platform from present to past and back again, we can immerse ourselves in their writings and thoughts as they interlink in ways that expose their similarities of vision, and values, gleaned from natural and computational worlds. As mathematicians, both observed nature in order to deepen their understanding of its processes, with an eye for patterns and a love of Euclidean geometry. While Turing broke secret codes, da Vinci wrote codes in secret texts and drawings, using real and symbolic imagery to open our eyes to the mysteries of the human mind and body. Working from new ideas of perspective in art and the science of painting that ushered in Renaissance ideology, Leonardo da Vinci uncovered the inner workings of human anatomy, detailing its machine-like qualities in his drawings while Turing engaged with the notion of intelligent machines noting that this, "would of course be met with great opposition, unless we have advanced greatly in religious toleration from the days of Galileo" [37], adding that "at some stage therefore we should have to expect the machines to take control" [35].

Thus, each moderated and influenced dominant religious beliefs of their time. Both were left-handed, so right-brain dominant associated with creativity [32] and both were intensely passionate about studying human states of being and thinking. Significantly, both men identified as gay, and for that personal expression of identity, faced persecution by state authorities. In this article, we explore the work of da Vinci and Turing using digital research methods on the web which drives new ways of thinking about how we think, which invites complexity, non-linear approaches and interdisciplinarity while revealing new contexts and connections. As we travel across the global digital ecosystem, we can see that da Vinci and Turing not only laid the foundations for the age of AI, and more than human art and life, but as well, they envisioned the Digital Renaissance we are experiencing today and into the future.

\section{DIGITAL DA VINCI - THE CODICES AND ARTWORKS}

\section{Breaking the Code - Human and Artificial Life}

Leonardo da Vinci and Alan Turing were pioneers of code breaking, da Vinci for revealing the mechanisms and processes of the human body as seen especially in his drawings of the beginning of life of the foetus in the womb, to the architecture of the brain based on his firsthand observation dissecting the body at death, while Turing, through his studies in morphogenesis and phyllotaxis, explained the processes and patterns of cellular formation, patterns of growth in plants, and implying the neural networks of the brain through its electrical currents, expressed as ones and zeros of a digital computer.

Digital da Vinci enables a new era of discovery into his mind and work. In the words of Alice Roberts, science professor at the University of Birmingham, "Leonardo saw the body as a complex, beautiful machine." In her article for The Guardian newspaper, she writes [30]:

For me, Leonardo's notebooks represent a triumph and a tragedy. How wonderful that we can see the workings of this man's mind, 500 years on. But how tragic that his own generation did not benefit from his discoveries. 
His notebooks lay unpublished for centuries. A few pages were copied and published as etchings at the end of the 18th century but it took until 1916 for all of Leonardo's anatomical papers to be published. They remain, to a modern anatomist's eye, utterly extraordinary and breath-taking in their scope and accuracy.

\section{The Human Machine - Body and Mind}

The neuroscientist Jonathan Pevsner, in evaluating da Vinci's work on the brain, writes that it represents, "an astonishingly sharp break from the field that had seen little if any progress in the previous 13 centuries. His work reflects the emergence of the modern scientific era and forms a key part of his integrative approach to art and science" [29]. The digitisation of da Vinci's notebooks has catapulted them into public consciousness, their digital images in lights on the Internet - we are amazed at their beauty and the breadth and depth of the innovation and discovery that they represent, having been virtually hidden for 500 years. Thus, with digitisation, we can read da Vinci's notebooks [27] in the contemporary context shedding new light on his ways of thinking and expressing his artistic and scientific vision.

Made freely accessible for the first time, the notebooks are having significant impact on our understanding of his work, while with the Turing Digital Archive online [39], we can go beyond his achievements and influence in computer science [7], AI and machine learning, to his studies in morphogenesis and embryology to arrive at his broad concepts of the processes of nature and the human brain. In light of Turing's work [16], we can look back to da Vinci and gain greater insight into the relevance of his work today and how both viewed the intrinsic beauty of nature and the mind human and body, from outside in and inside out, and the patterns and shapes of flowers and human form as they development.

\section{Visualising da Vinci: The Codex Atlanticus}

The Biblioteca Ambrosiana in Milan, working with the design firm Visual Agency, have produced a highly effective interactive visualisation of the Codex Atlanticus [3] that allows users to search the 1,119 leaves of this 12-volume collection in new and innovative ways. This Codex constitutes the largest collection of da Vinci drawings and texts. Its brown leather cover adorned with gold lettering reads, "DISEGNI-DI-MACHINE-ET-DELLE-ALTRE-COSERACOLTI DA POMPEO LEO" (Pompeo Leoni, Italian sculptor and medallist, born 1533 in Milan, died 1608 in Madrid). This collaborative digital rendering of the Codex Atlanticus no doubt points to future developments in interactive visualisations of digital text and images for discovery. See Figure 1 below. 


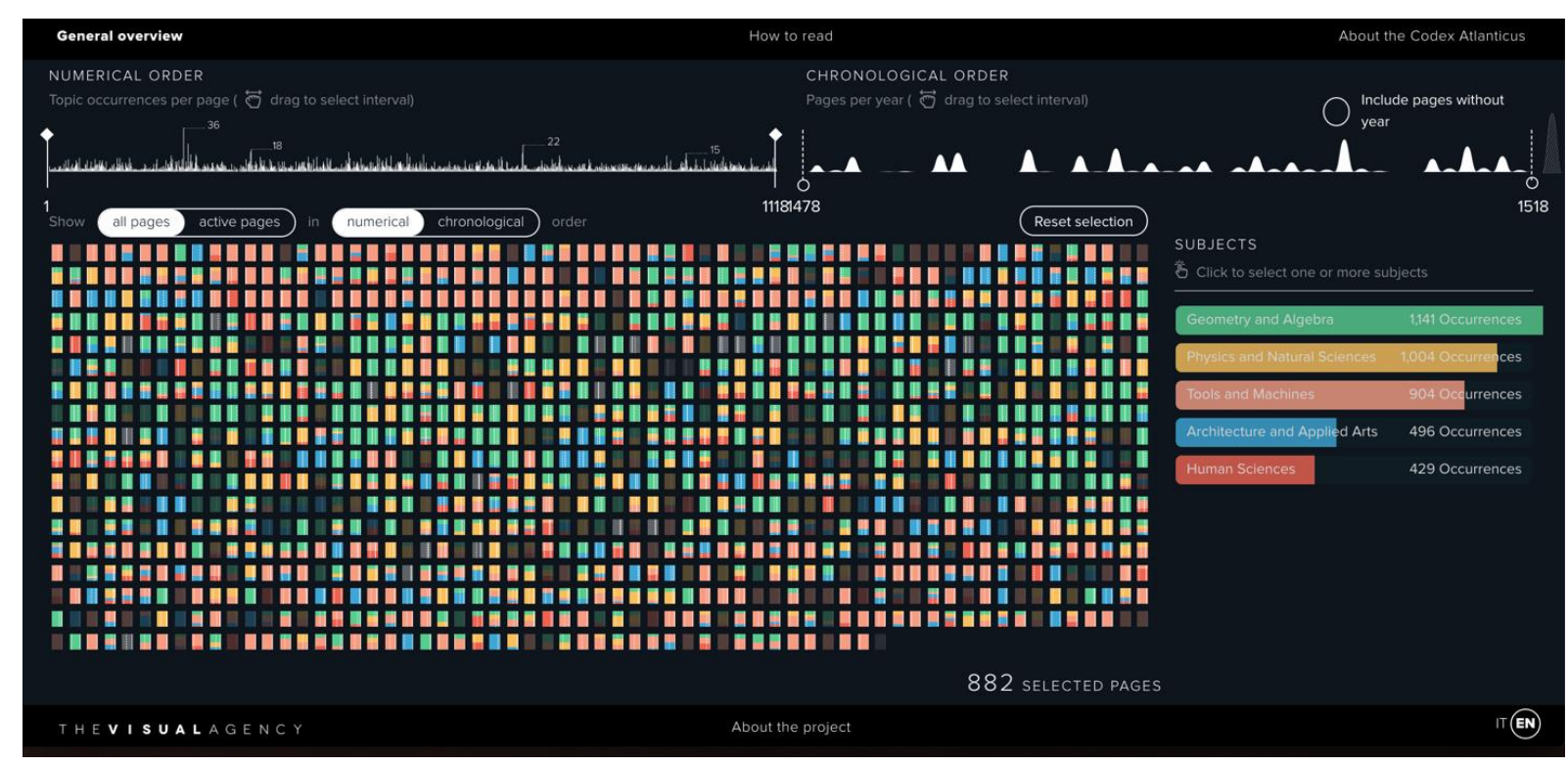

Fig. 1. Codex Atlanticus - Screen shot of its interactive visualisation (http://www.codex-atlanticus.it/\#/Overview).

\section{Codex Arundel - MS 263 British Library}

The Codex Arundel was owned by Thomas Howard (1585-1646), 2nd Earl of Arundel, 4th Earl of Surrey, and 1st Earl of Norfolk, art collector and politician, and then owned by Henry Howard (1628-1684), 6th Duke of Norfolk, who in 1667 presented the Codex Arundel to the Royal Society in London. In 1831, the British Museum purchased the Codex with 549 other Arundel manuscripts from the Royal Society. The Codex is currently housed in the British Library [2], where it has been fully digitised. After its long aristocratic past of minimal access, happily, it has been made available online for public view; its 283 folios (570 images) can be viewed by anyone on the British Library website, including magnification facilities (http://www.bl.uk/manuscripts/Viewer.aspx?ref=arundel_ms_263_f001r).

\section{The Codex Leicester on Display in Florence}

The Codex Leicester (https://mostre.museogalileo.it/codiceleicester/en/codex), privately owned by Bill Gates, was featured at the Uffizi Gallery in Florence for the exhibition Water as Microscope of Nature, which was on view from 30 October 2018 to 20 January 2019. Also in Florence, the Museo Galileo mounted two exhibitions on da Vinci - Leonardo in Valdichiana: A Map of the Territory and the Science of Water, August 2019, which ties to the Uffizi exhibition, and Leonardo da Vinci and Perpetual Motion from October 2019 to January 2020 (see Figure 2). The exhibition website uses 3D video animation to illustrate perpetual motion which da Vinci concluded was not possible in nature [43]. 


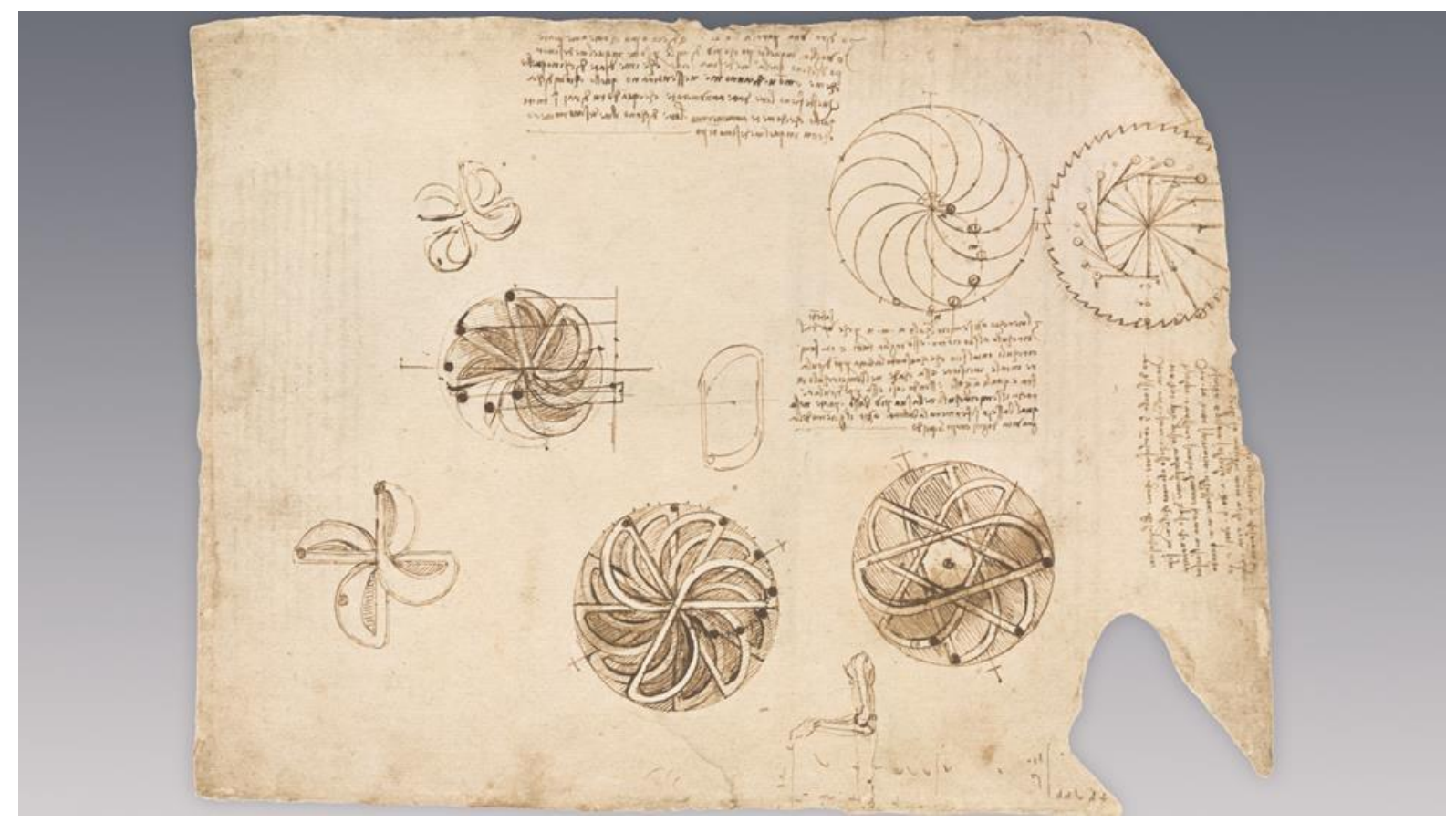

Fig. 2. Leonardo da Vinci drawing from the Codex Atlanticus, f1062r, on view at the 2019-20 Museo Galileo exhibition Leonardo da Vinci and Perpetual Motion (https://mostre.museogalileo.it/motoperpetuo/en/?_ga=2.205581971.1647228362.1573505300-1512439500.1573505300).

Also known as the "Hammer" codex from the name of the American millionaire who owned it before Bill Gates, the Codex Leicester was compiled between 1506 and 1513, during the period when Leonardo da Vinci was dividing his time between Florence and Milan, under the protection the French king, Louis XII. Unique to this Codex, it is almost entirely concerned with the study of water in the natural landscape, such as its shapes, movements and flow. The Codex was on exhibition in London at the British Library during summer 2019, which was the first time it was available for public view in the UK since Gates purchased it in 1994 [15].

\section{MUSEUM EXHIBITIONS: FLORENCE, PARIS AND LONDON}

The global celebration of 500 years since the death of Leonardo da Vinci takes us back in time to the Italian Renaissance to mark the birth of humanism most vividly defined and visualised by da Vinci's work. His observations of the natural world and the human mind and body as seen in his notebooks and paintings, now inspire us to more closely observe what it means to be human in the age of AI and artificial life. Are we not surprised that we find answers and insights in his notebooks and more than real paintings?

In Florence, the Palazzo Strozzi featured a retrospective exhibition of 120 paintings, sculptures and drawings, including those of da Vinci and his teacher, Andrea del Verrocchio, and other pupils, that ran between 9 March - 14 July 2019. In September 2019, a curated version of the show was on view at The National Gallery of Art in Washington, D.C., and at the Denver Museum of Nature and Science, the exhibition Leonardo da Vinci: 500 Years of Genius, which displayed reproductions of Leonardo's inventions and a 360-degree replica of the Mona Lisa. The exhibition at the Louvre Museum in Paris, which houses nearly a third of Leonardo da Vinci's surviving artworks, including the Mona Lisa, was a retrospective of the artist's paintings that opened in October 2019. Vincent Delieuvin, a co-curator, notes that "We want to illustrate how he placed utmost importance on painting and how his investigation of 
the world, which he referred to as 'the science of painting,' was the instrument of his art, seeking nothing less than to bring life to his paintings" [45] and why King Charles I of England's prize painting was da Vinci's St Jerome [25]. Although the Mona Lisa was not included in the exhibition, it was on display in the Louvre, and its appearance complimented by a VR show of the Mona Lisa, designed for the Louvre by Vive Arts, created an enormous sensation [44]. In London, the Barbican exhibition, AI: More than Human [24], took visitors on a journey in time beginning with many of the iconic objects, images and leaders of AI development from the 1940s and 1950s to the present, especially Alan Turing. Figure 3 shows two works on view.

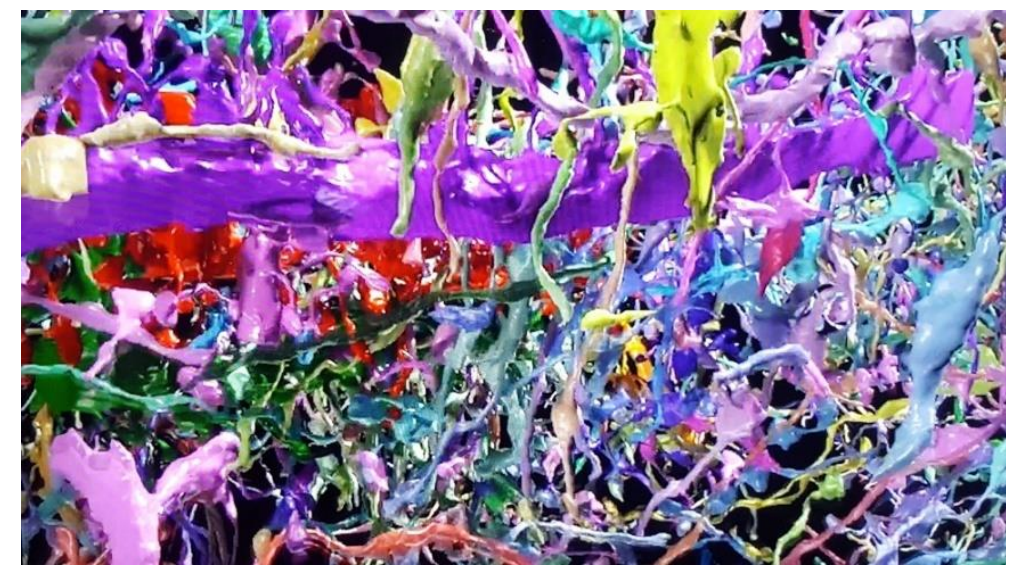

Fig. 3a. "Unlocking the Brain - The human brain is an incredibly sophisticated machine that excels at a multitude of tasks. Scientists around the work are attempting to recreate its most complex processes to potentially improve AI. Surprisingly a crucial tool in pursuing this research has been AI itself."

(Quoted from the exhibition label.)

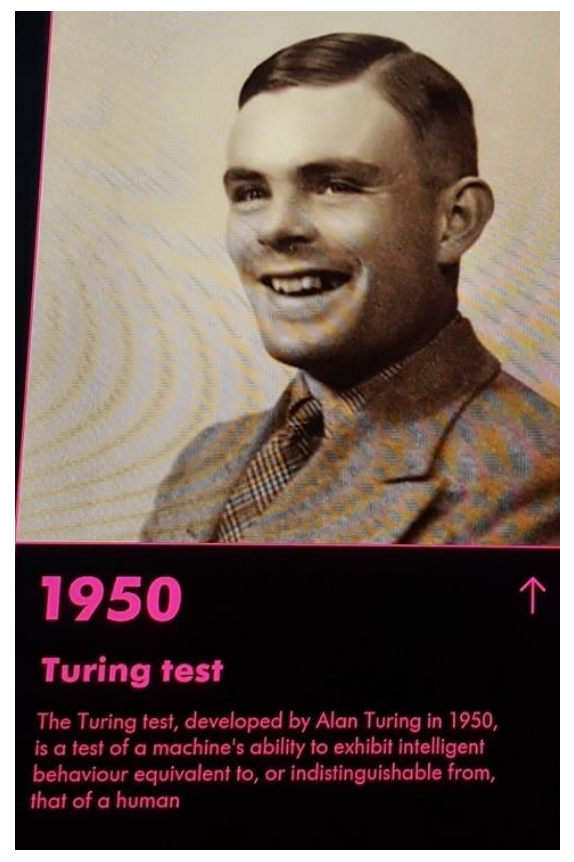

Fig. 3b. Alan Turing photo with exhibition text.

\section{DIGITAL HUMANISM IN SCIENCE AND ART}

\section{Soundscapes of Da Vinci's World}

As we visualise the sights and sounds of da Vinci's environs, we hear the music of Philippe Verdelot (c.1480s-1530s) [42], the most prominent composer of his time, who spent his career in Italy working in Rome and Florence supported by the Medici family. He is recognised as the father of the madrigal, a musical form that inspired the great composers of his day and into the late Renaissance, including Monteverdi and Gesualdo. Da Vinci's affinity for music is seen in his inventions for key systems for wind instruments. The drawing in Figure 4 confirms Leonardo's interest in musical instruments and his advanced knowledge of key mechanisms. He compares the poet, painter and musician writing [28]:

When the poet ceases to represent in words what exists in nature, he then ceases to be the equal of the painter... But if he returns to the representation of some definite thing he would become the equal of the painter if he could satisfy the eye with words as the painter does with brush and colour, [for 
with these he creates] a harmony to the eye, even as music does in an instant to the ear.

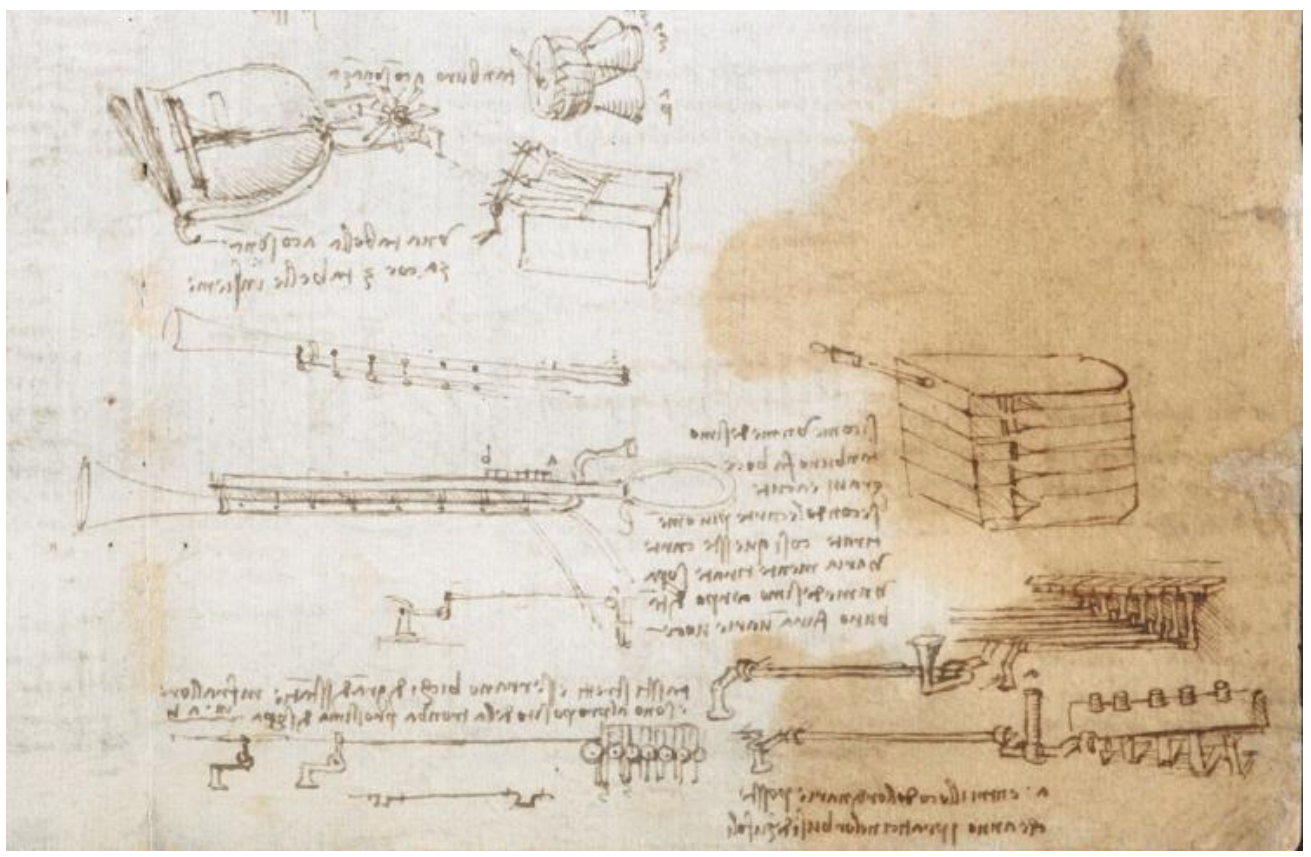

Fig. 4. Drawing by Leonardo da Vinci of various musical wind instruments. Arundel Codex, 175r. British Library.

During first decade of the $16^{\text {th }}$ century, the French composer Philippe Verdelot (see Figure 5) worked in Florence and Rome. He became known for the development of the Italian madrigal, as its leading composer. The Verdelot madrigal brings together voice and instruments set to the poetry of the likes of Petrarch evoking a visualisation of human expression, a soundscape of the da Vinci milieu. He collaborated with Niccolò Machiavelli (1469-1527) on his comedies. His compositions continued to be popular throughout the $16^{\text {th }}$ century such as his madrigal, Italia mia [41], set to the poetry of Petrarch that appeals for truth and peace.

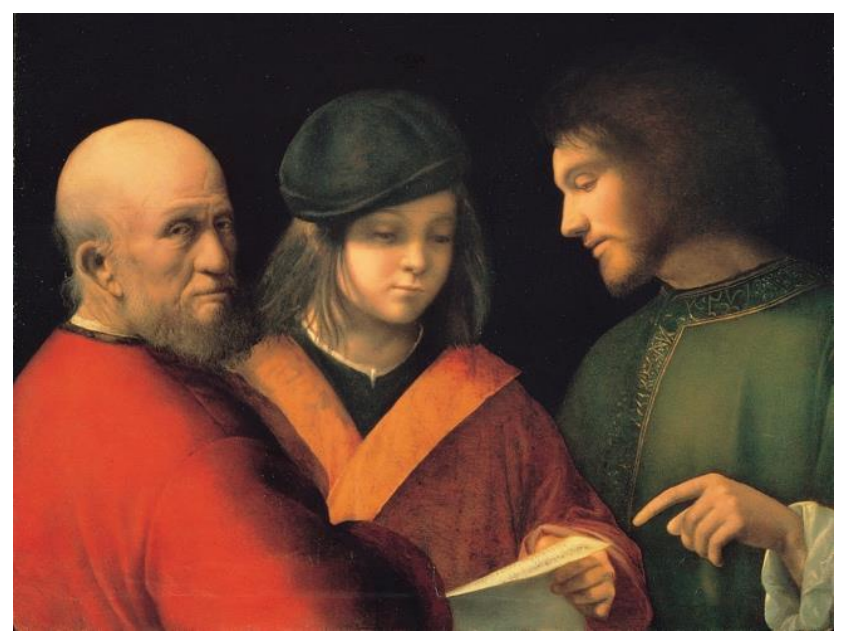

Fig. 5. The Three Ages of Man (or Reading a Song), painting by Giorgione (c.1501). Left to right, Jacob Obrecht (composer), Sebastiano Luciano, and Philippe Verdelot.

Galleria Palantina, Palazzo Pitti, Florence. Wikimedia Commons

(https://commons.wikimedia.org/wiki/File:Giorgione_-_Three_Ages_of_Man_-_Palazzo_Pitti.jpg). 


\section{Mother and Child - Body and Soul}

The female body and soul dominated da Vinci's consciousness and seeing. His most favoured subject matter in terms of his paintings seems to be that of the mother and child, while among his drawings, the series on the foetus in the womb contained in the Windsor Notebook draws much public attention and was featured in the 2019 da Vinci exhibition at the Queen's Gallery, Buckingham Palace. Understanding their power to stir human emotion was vividly expressed by the Gallery's poetry competition to which visitors were invited to submit poems inspired by the drawings [31]. According to Hilary Gilson of the Embryo Project at Arizona State University, Leonardo da Vinci's work in embryology was groundbreaking. He observed and diagrammed the previously undemonstrated position of the foetus in the womb with detailed accompanying annotations of his observations [23].

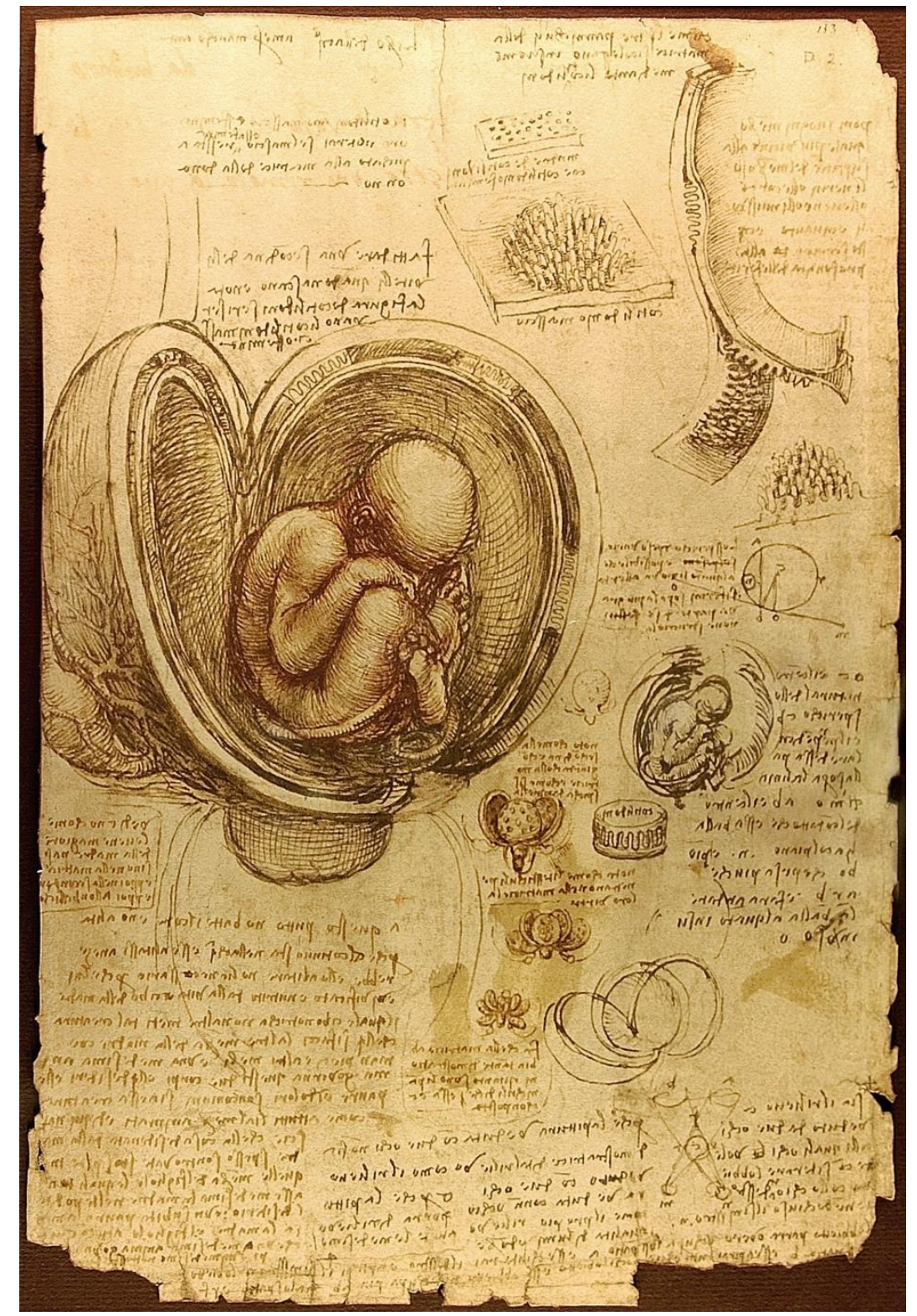

Fig. 6. Studies of Embryos by Leonardo da Vinci (pen over red chalk 1510-1513).

Wikimedia Commons (http://commons.wikimedia.org/wiki/File:Da_Vinci_Studies_of_Embryos_Luc_Viatour.jpg). 
Figure 6 is a drawing by Leonardo da Vinci from his series of drawing of the foetus in the womb, and his studies on embryology (Windsor Library Notebook) It is one of the two drawings on this subject displayed in the Queen's Gallery, Buckingham Palace for the exhibition Leonardo da Vinci: Anatomist, which served to inspire the Poetry Society in the UK to hold a poetry competition that was judged by Clive Wilmer, British poet and fellow at Cambridge University. He wrote [31]: "Most of the poets were either appalled or fascinated by the creative mind the drawings suggest: the emotional detachment needed, the precision of hand and eye, the reverence for life."

Although the competition poems do suggest "emotional detachment", from the perspective of the human interaction between mother and child, they bring focus to their physical and emotional bonds and the process that transforms the foetus in the womb to mother and child, while the competition poems seem to interpret the subject matter as rendered by da Vinci from a more technical and clinical perspective. This inspired Giannini to write the following poem around the notion of a conversation and relationship between mother and child, a foetus in the process of becoming a child. Clearly, for da Vinci, the subject was one of intense study and reflection, and we see the mother and child pictured in 10 out of his c.14 known paintings (see Figure 7 for example), and in his series of drawing on the foetus and womb reminding us of his strong emotional ties to his own mother, while some historians speculate that da Vinci painted the Mona Lisa in her likeness. Turing also was close with his mother, Sara Turing (1881-1976). She took custody of his archives and wrote the biographical book, Alan M. Turing, originally published in 1959 and revised in 2012 for Alan Turing's centenary [40]. The rich correspondence between them survives.

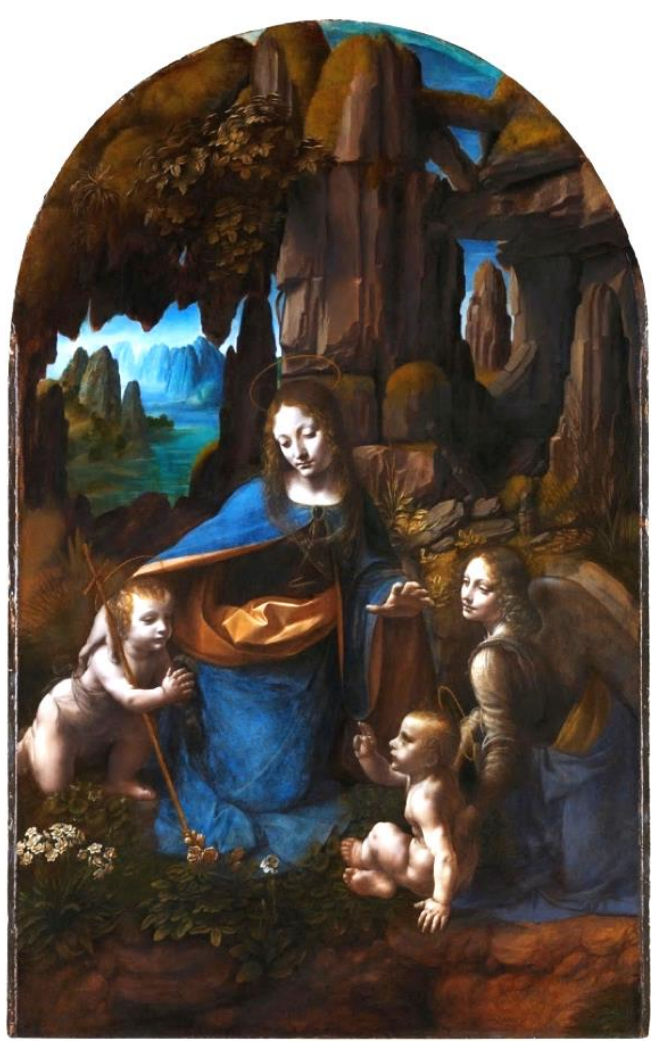

Fig. 7. Virgin of the Rocks by Leonardo da Vinci, completed 1508. National Gallery, London. The virgin with the infant saint.

\section{Mother and Child}

(by Tula Giannini, 2019)

My child -

Cry not silently

I can't see your face

Can't embrace

Your head hangs down

Your face hidden between hands

No Instagram

My Mother -

Dreaming of you

I hear your silent voice

Hold me close

Lift me up

Let me breathe

Breathe in your smell

Hold me

close to your breast

Let me drink

your heavenly nectar of life

and think, of you 


\section{Decoding da Vinci}

With the decoding of da Vinci's handwriting and the translation and digitisation of the texts incorporated into his drawings, we discover what his series of drawings on the foetus and womb meant to him. This digitally liberated text found on the Internet Archive is from Edward MacCurdy's translation of Leonardo da Vinci's notebooks [27]. It is astonishing to learn that he writes, "that it is the soul of the mother which first constructs within the womb the shape of the man, and in due time awakens the soul that is to be its inhabitant" (quoted from the text below [27]), which he defines as a process of nature entrusted to the mother that gives birth to a human being with heart and soul [27]:

Although human subtlety makes a variety of inventions answering by different means to the same end, it will never devise an invention more beautiful, more simple, or more direct than does nature, because in her inventions nothing is lacking, and nothing is superfluous; and she needs no countervailing weights when she creates limbs fitted for movement in the bodies of the animals, but puts within them the soul of the body which forms them, that is the soul of the mother which first constructs within the womb the shape of the man, and in due time awakens the soul that is to be its inhabitant. For this at first remained asleep, in the guardianship of the soul of the mother, who nourishes and gives it life through the umbilical vein, with all its spiritual members, and so it will continue for such time as the said umbilical cord is joined to the placenta- and the cotyledons [a lobule of mammalian placenta - also, an embryonic leaf in seed-bearing plants, one or more of which are the first leaves to appear from a germinating seed.] by which the child is attached to the mother. And this is the reason why any wish or intense desire fright experienced by the mother, or any other mental suffering, is felt more powerfully by the child than by the mother, for there are many cases in which the child loses its life from it.

The Leonardo da Vinci notebook that belongs to the Queen's Library at Windsor Castle in the UK is composed of more than 600 sheets that were brought together in a leather binding by Pompeo Leoni (1533-1608), an Italian sculptor of the late Renaissance. The gilt letters on the cover read, Drawings by Leonardo da Vinci restored by Pompeo Leoni. Considered by many to be da Vinci's most awe-inspiring notebook and exceptional among the codices for its anatomical drawings of the foetus and womb as seen above, it is thought by Jonathan Jones, art critic for The Guardian newspaper, to be the most important of da Vinci's notebooks [26].

\section{Neuroscience - The Human Brain and the Senses}

Leonardo da Vinci wrote [27]: "the common sense is the seat of the soul, and the memory is its monitor, and its faculty of receiving impressions serves as its standard of reference." He thought that information passed to and through the fluid-filled ventricles rather than brain matter (see Figure 8), writing [17]:

The senses are moved by the objects; and these objects send their images to the five senses by which they are transferred to the imprensiva [da Vinci's term and concept], and from this to the senso commune. From thence, being 
judged, they are transmitted to memory, in which according to their power they are retained more or less distinctly.

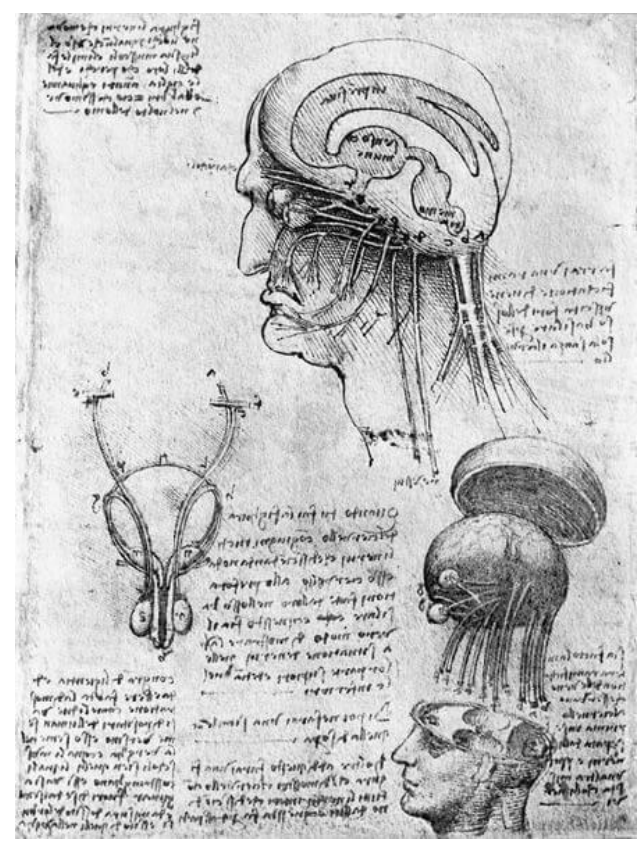

Fig. 8. Drawing of the brain by Leonardo da Vinci in 1510, showing cerebral ventricles and cranial nerves. Wikimedia Commons (https://commons.wikimedia.org/wiki/File:Leonardo_Da_Vinci\%27s_Brain_Physiology.jpg).

Turing, like da Vinci, studied the flow of information to and from the human brain by way of neural networks of interaction through the senses. Recent advances by the computer scientists receiving the 2018 A. M. Turing Award [1] focus on AI, machine learning, and the senses: seeing, hearing, reading, and speaking.

\section{SEEING NATURE - INSPRIRING ART AND SCIENCE}

Leonardo da Vinci felt that a painter could only achieve perfection and originality by taking nature as his standard. Thus, he links the study of nature and original work, and warns against imitating others' work, which led to the decline of art, a notion that rings true with contemporary art. To quote Leonardo da Vinci in translation [27]:

The painter will produce pictures of little merit if he takes the works of others as his standard; but if he will apply himself to learn from the objects of nature, he will produce good results. This we see was the case with the painters who came after the time of the Romans, for they continually imitated each other, and from age to age their art steadily declined.

After these came Giotto the Florentine ... turning straight from nature to his art ... began to draw the figures of all the animals which were to be found in the country, in such a way that after much study he not only surpassed the masters of his own time but all those of many preceding centuries. After him art again declined... until such time as Tommaso the Florentine, nicknamed Masaccio, showed by the perfection of his work how those who took as their 
standard anything other than nature, the supreme guide of all the masters, were wearying themselves in vain.

\section{Turing and da Vinci - Kindred Spirits}

The Turing Test, devised to compare human and machine intelligence deploying AI and machine learning, begs the question, can robots be "more than human" [24]. At the heart of artificial life (A-Life) is the process of simulating nature, what might be called "digital nature" as we see in the latest research on using mapping neural networks of the human brain using AI. The connections their work makes across art, nature, science and technology, is still groundbreaking in our $21^{\text {st }}$-century world. But perhaps it is with the ties between nature, math and computing, where human and artificial neural networks come together as one in ways that challenge the nature of being human, thinking and consciousness.

Turing's work on morphogenesis, considering the algorithms of nature that instruct the processes generating life itself, reflects his work with digital computers to simulate that process for which he developed AI and machine learning. Turing asks [36]: "How much information could be stored in the human brain in this way?" Here he is referring to the number of neurons. He writes: "The answer is simply MN binary digits, for there are MN paths each capable of two states," (where $\mathrm{M}$ is the number of outlets and $\mathrm{N}$ is the number of neurons) and goes on to say that, "the particular combinations which will be facilitated will not be fixed at birth but determined by training." Thus, he connects the embryology of plants and humans (see Figure 9), and the neural networks and processes of the human brain, which determine development based on binary digits that can be turned on and off. From the images in Figure 10, we see that both Turing and da Vinci studied flowers and their patterns to gain insight into the "mathematical theory of embryology", a phrase Turing uses in his typescript below.

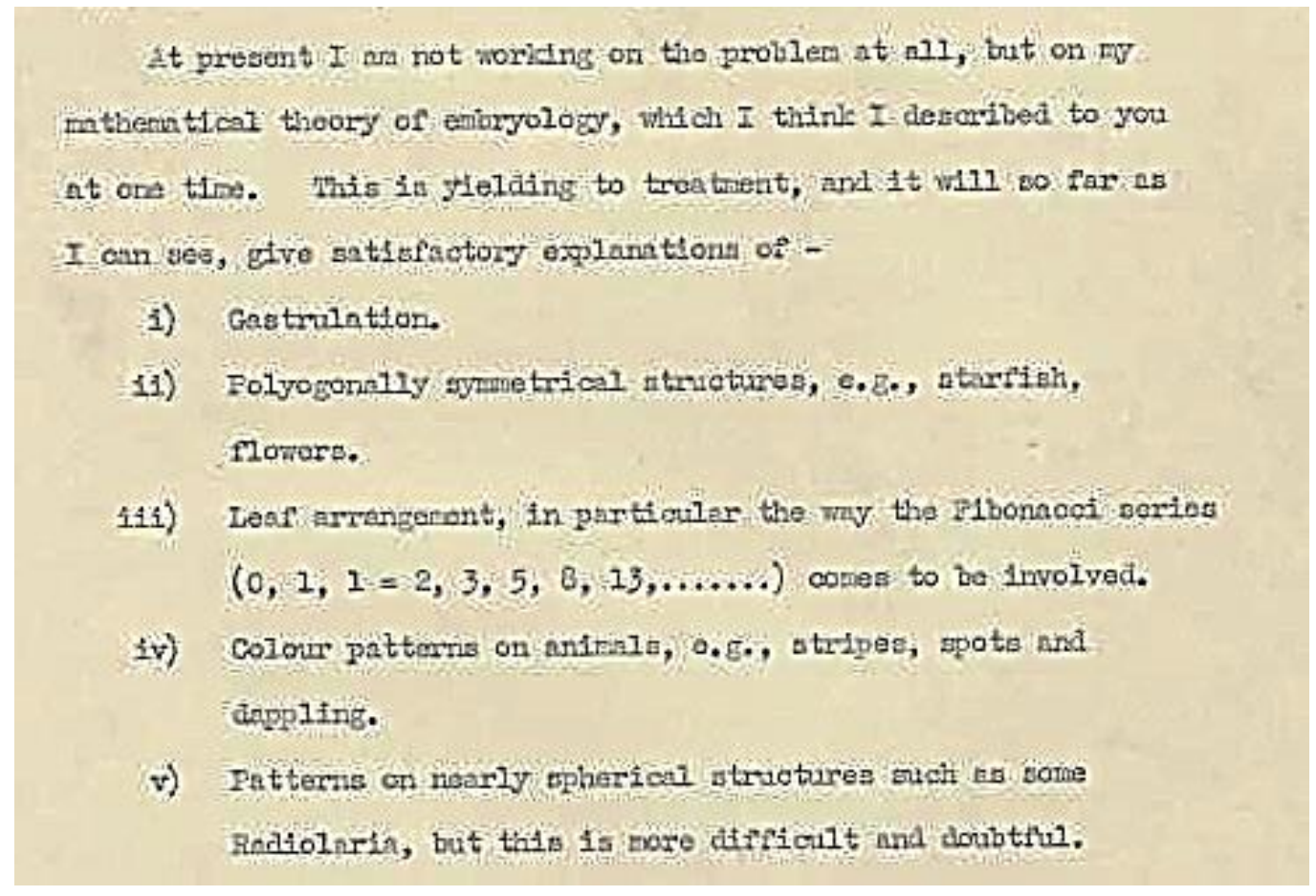

Fig. 9. Excerpt from letter dated 8 February 1951, Turing to Professor J. Z. Young on brain structure and the storage capacity from Turing's work, a mathematical theory of embryology.

AMT/K/78: image 78a (http://www.turingarchive.org/viewer/?id=439\&title=78a) [36]. 


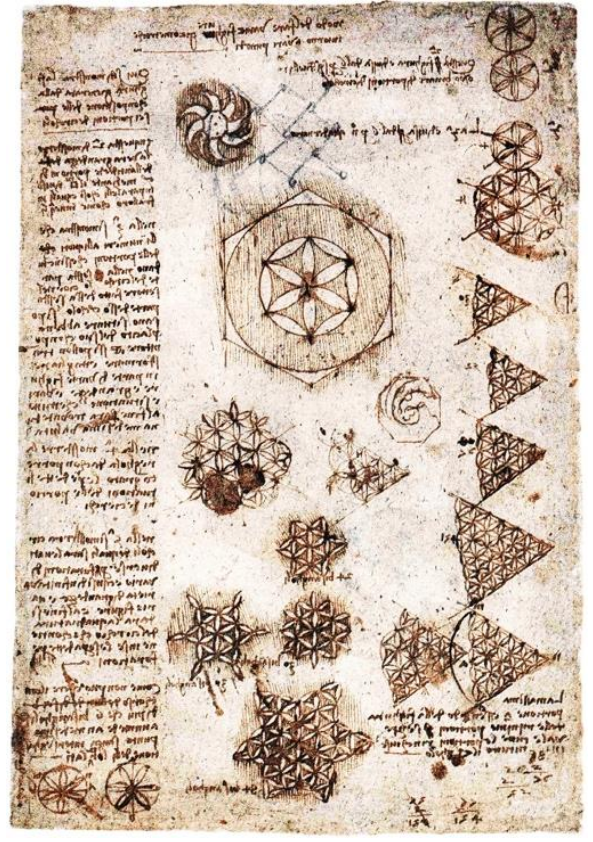

Fig. 10a. Leonardo da Vinci, Codex Atlanticus, folio 459r. This is one of da Vinci's drawings of geometrical structures related to the ornamental structure named today "flower of life". Wikimedia Commons (https://commons.wikimedia.org/wiki/File:Leonardo_da_Vi nci_\%E2\%80\%93_Codex_Atlanticus_folio_459r.jpg).

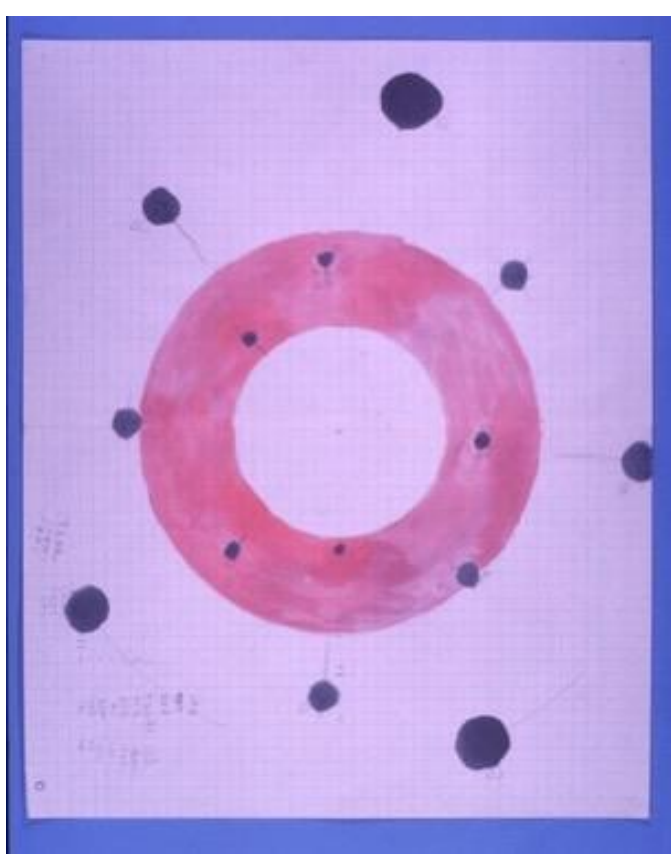

Fig. 10b. Daisy ring diagram by Alan Turing. Coloured diagram in connection with work on morphogenesis. AMT/K/3 image 3, Turing Digital Archive

(http://www.turingarchive.org/viewer/?id=450\&title=3) [39].

\section{Can Computers Think? - by Alan Turing}

The work of da Vinci and Turing reveals humanistic perspectives on art and human identity and has sparked revolutionary changes in the ways we see and express the underlying connections between nature, art, and science. Da Vinci's pioneering work was foundational to transitioning to the Enlightenment, while Turing's introduction of computer science [33], AI, machine learning and thinking [34], sparked the digital revolution paving the way for the age of AI. Turing's reflections on the reach of AI and computing show that he did not impose any limitations.

Today, these connections between the physical and digital world are essentially AI and machine learning in a human context. As we see with the Turing Test, he never lost sight of the "thinking machine" in relationship to the human mind [34]. On May 15, 1951, Turing gave a talk for the BBC with the title, "Can Digital Computers Think?" (see Figure 11). Turing ends by saying [37]: "The whole thinking process is still rather mysterious to us, but I believe that the attempt to make a thinking machine will help us greatly in finding how we think ourselves." 


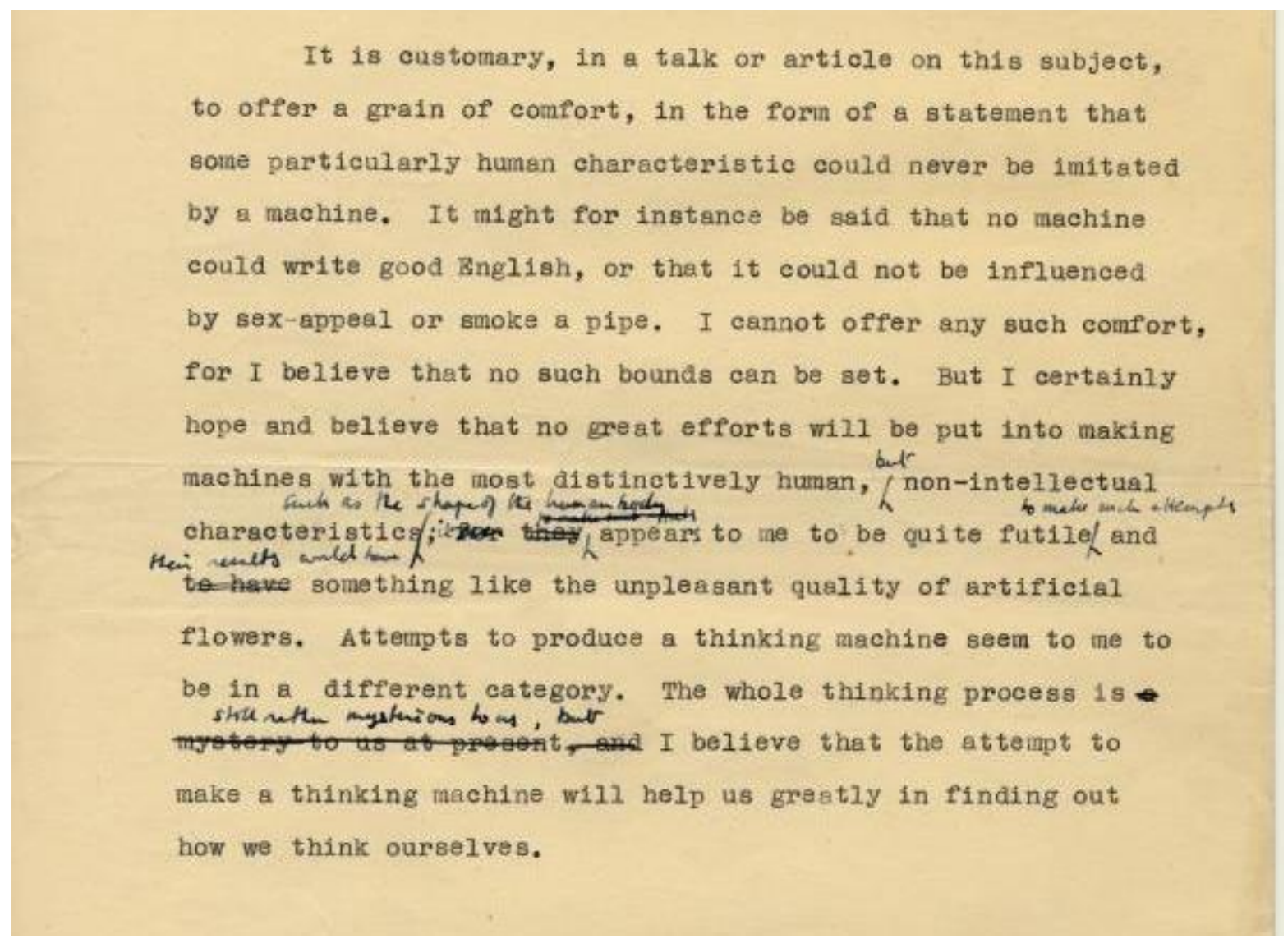

Fig. 11. Typescript with annotations from the talk, "Can digital computers think?"

by Alan Turing, broadcast on the BBC, 15 May 1951.

(http://www.turingarchive.org/viewer/?id=459\&title=8) [37].

\section{CONCLUSION}

In many ways Leonardo da Vinci and Alan Turing define what we now see as our postdigital world - a world in which the material and virtual, physical and digital states of being are becoming integrated - part of a living ecosystem at once natural, artificial, real and simulated, that can be understood across neural and digital networks that are fuelling the Digital Renaissance. Because da Vinci's notebooks were not publicly accessible until the late $19^{\text {th }}$, early $20^{\text {th }}$ century, and their digitisation and online publication is a relatively recent development [27], they are encouraging new research and public engagement that enables researchers to gain a deeper understanding and appreciation of his work.

Similarly, Turing gained wide recognition during World War II for his work on code breaking which lead to his stunning breakthroughs in computer science in the 1950s, while at the same time, being a gay computer scientist, he suffered the consequences of the UK's antigay legislation which in many respects lead to his untimely death in 1954. With the availability of the Turing Digital Archive at King's College, Cambridge, researchers and the general public now have access to some 3,000 documents online [39]. Reading these documents is like hearing the words of Turing and his circle as we gain a fuller understanding of his of thinking and can see that he envisioned current developments in AI and machine learning and was able to intuit the future of the field which is sparking new conversations and questions that open our mind 
to the inherent relationships of science, art, technology and culture. In this context a new social and cultural order is emerging.

With the embrace of diversity and individual identity, the legacy of da Vinci and Turing moves front and centre in the fields of HCI, art, and technology, as it sets the stage for what can be achieved in the Digital Renaissance of the $21^{\text {st }}$ century. Both da Vinci and Turing were intense observers of the natural world, inspiring them in science [4] and art. These newly found relationships of postdigital thinking are integrating machine and human learning, so that increasingly, natural and artificial life inhabit the global ecosystem, where encounters between da Vinci and Turing transpire and inspire - all part of the Digital Renaissance.

\section{ACKNOWLEDGEMENTS}

This paper has taken inspiration from a recent book [21] and previous EVA London conference [47] papers [5], [10]-[13], [18]-[20]. The paper has an associated sister paper [22] in EVA London 2020 [48]. Thank you especially to Vito Cappellini of EVA Florence for encouragement in writing this paper. We dedicate this paper to all those involved with EVA Florence in these difficult times. We also specifically dedicate this paper to Kim Veltman, friend of EVA, historian of art and science, and a scholar of Leonardo da Vinci [49], who sadly succumbed to COVID-19 on 1 April 2020. Jonathan Bowen is grateful to Museophile Limited for financial support.

\section{REFERENCES}

[1] ACM (2018) Fathers of the Deep Learning Revolution Receive ACM A.M. Turing Award. Association for Computing Machinery. URL:

https://awards.acm.org/about/2018-turing

[2] BL (n.d.) Arundel MS 263. Digitised Manuscripts, British Library, London, UK. URL: http://www.bl.uk/manuscripts/FullDisplay.aspx?ref=Arundel_MS_263

[3] Bonera, M. et al. (n.d.) Codex Atlanticus. The Visual Agency, Milan, Italy. URL: http://codex-atlanticus.it

[4] Bowen, J. P. (2012) Alan Turing. In A. Robinson (ed.), The Scientists: An Epic of Discovery. Thames and Hudson, pp. 270-275.

[5] Bowen, J. P. (2016) Alan Turing: Virtuosity and visualisation. In [8], pp. 197-204. DOI: https://doi.org/10.14236/ewic/EVA2016.40

[6] Bowen, J. P. (2017) Alan Turing: Founder of Computer Science. In J. P. Bowen, Z. Liu, and Z. Zhang (eds.), Engineering Trustworthy Software Systems: Second International School, SETSS 2016, Chongqing, China, March 28 - April 2, 2016. Springer, LNCS, vol. 10215, pp. 1-15. DOI: https://doi.org/10.1007/978-3-319-56841-6_1

[7] Bowen, J. P. (2019) The Impact of Alan Turing: Formal Methods and Beyond. In J. P. Bowen, Z. Liu, and Z. Zhang (eds.), Engineering Trustworthy Software Systems: Second International School, SETSS 2018, Chongqing, China, April 7-12, 2018. Springer, LNCS, vol. 11430, pp. 202-235. DOI: https://doi.org/10.1007/978-3-030-17601-3_5

[8] Bowen, J. P., Diprose, G., and Lambert, N. (eds.) (2016) EVA London 2016: Electronic Visualisation and the Arts. BCS, Electronic Workshops in Computing (eWiC). ScienceOpen. DOI: https://doi.org/10.14236/ewic/EVA2016.0 
[9] Bowen, J. P., Diprose, G., and Lambert, N. (eds.) (2017) EVA London 2017: Electronic Visualisation and the Arts. BCS, Electronic Workshops in Computing (eWiC). ScienceOpen. DOI: https://doi.org/10.14236/ewic/EVA2017.0

[10] Bowen, J. P., Giannini, T., Ara, R., Lomas, A., and Siefring, J. (2019) States of Begin: Art and identity in digital space and time. In [47], pp. 1-9. DOI: https://doi.org/10.14236/ewic/EVA2019.1

[11] Bowen, J. P., Giannini, T., and Polmeer, G. (2017) Coded Communication: Digital senses and aesthetics, merging art and life. In [9], pp. 1-8. DOI: https://doi.org/10.14236/ewic/EVA2017.1

[12] Bowen, J. P., Giannini, T., Polmeer, G., Gannis, C., Gardiner, J., Kearney, J., Wands, B., and Weinel, J. (2018) States of Begin: Art and identity in digital space and time. In [14], pp. 1-7. DOI: https://doi.org/10.14236/ewic/EVA2018.1

[13] Bowen, J. P., Trickett, T., Green, J. B. A., and Lomas, A. (2018) Turing's Genius Defining an apt microcosm. In [14], pp. 155-162. DOI:

https://doi.org/10.14236/ewic/EVA2018.31

[14] Bowen, J. P., Weinel, J., Diprose, G., and Lambert, N. (eds.) (2018) EVA London 2018: Electronic Visualisation and the Arts. BCS, Electronic Workshops in Computing (eWiC). ScienceOpen. DOI: https://doi.org/10.14236/ewic/EVA2018.0

[15] Brown, M. (2019) Rare Leonardo da Vinci notebook to go on show at British Library. The Guardian, 4 December. URL:

https://www.theguardian.com/artanddesign/2018/dec/04/rare-leonardo-da-vincinotebook-to-go-on-show-at-british-library

[16] Copeland, B. J., Bowen, J. P., Sprevak, M., Wilson, R. J., et al. (2017) The Turing Guide. Oxford University Press. URL: https://en.wikipedia.org/wiki/The_Turing_Guide

[17] Fessi, S. (2019) The Hidden Neuroscience of Leonardo da Vinci. Dana Foundation, 23 September. URL: https://dana.org/article/the-hidden-neuroscience-of-leonardo-da-vinci/

[18] Giannini, T. and Bowen, J. P. (2016) Curating Digital Life and Culture: Art and information. In [8], pp. 237-244. DOI: https://doi.org/10.14236/ewic/EVA2016.46

[19] Giannini, T. and Bowen, J. P. (2017) Life in Code and Digits: When Shannon met Turing. In [9], pp. 51-58. DOI: https://doi.org/10.14236/ewic/EVA2017.9

[20] Giannini, T. and Bowen, J. P. (2018) Of Museums and Digital Culture: A landscape view. In [14], pp. 172-179. DOI: https://doi.org/10.14236/ewic/EVA2018.34

[21] Giannini, T. and Bowen, J. P. (eds.) (2019) Museums and Digital Culture: New perspectives and research. Series on Cultural Computing. Springer.

[22] Giannini, T. and Bowen, J. P. (2020) Computing the Future: Digital Encounters in Art and Science When da Vinci Meets Turing. In [48], pp. 16-23. DOI:

https://doi.org/10.14236/ewic/EVA2020.3

[23] Gilson, H. (2019) Leonardo da Vinci's Embryological Annotations. The Embryo Project Encyclopedia, 19 August. Arizona State University. URL: http://embryo.asu.edu/handle/10776/1928

[24] Google (2019) AI: More than Human. Barbican exhibition, Google Arts \& Culture. URL: https://artsandculture.google.com/project/ai-more-than-human

[25] Hart, K. (2018) King Charles I Amassed One of the World's Greatest Art Collectionsthen Lost it All. Artsy, 1 March. URL: https://www.artsy.net/article/artsy-editorial-kingcharles-amassed-one-worlds-greatest-art-collections-lost 
[26] Jones, J. (2006) The real Da Vinci code. The Guardian, 30 August. URL: https://www.theguardian.com/artanddesign/2006/aug/30/art1

[27] MacCurdy, E. (1923) Leonardo da Vinci's Notebooks, arranged and rendered into English. Empire State Book Company. Archive.org. URL:

http://archive.org/stream/leonardodavincis007918mbp/leonardodavincis007918mbp_dj vu.txt

[28] MacCurdy, E. (1938) The Notebooks of Leonardo da Vinci, arranged and rendered into English. Volume II. Jonathan Cape. Archive.org. URL:

https://archive.org/stream/in.ernet.dli.2015.283546/2015.283546.The-

Notebooks_djvu.txt

[29] Pevsner, J. (2019) Leonardo da Vinci's studies of the brain. The Lancet, 393(10179), pp. 1465-1472, 6 April. DOI: https://doi.org/10.1016/S0140-6736(19)30302-2

[30] Roberts, A. (2012) Leonardo saw the body as a complex, beautiful machine. The Guardian, 13 May. URL: https://www.theguardian.com/science/2012/may/13/leonardoda-vinci-anatomy-drawings

[31] Royal Collection Trust (2019) Poetry Competition. Leonardo da Vinci, The Queen's Gallery, Buckingham Palace, UK. URL:

https://www.rct.uk/collection/themes/exhibitions/leonardo-da-vinci/the-queens-gallerybuckingham-palace/poetry-competition

[32] Tigar, L. (2018) Psychologists explain how left-handed people work differently. Fast Company, 13 August. URL: https://www.fastcompany.com/90215373/psychologistsexplain-how-left-handed-people-work-differently

[33] Turing, A. M. (1936) On computable numbers with an application to the Entscheidungsproblem, Proceedings of the London Mathematical Society, Series 2, 42(1), pp. 230-265. DOI: https://doi.org/10.1112/plms/s2-42.1.230

[34] Turing, A. M. (1950) Computing machinery and intelligence. Mind, 59(236), pp. 433460, October. DOI: https://doi.org/10.1093/mind/LIX.236.433

[35] Turing, A. M. (1951) Intelligent machinery, a heretical theory', a lecture given to '51 Society' at Manchester. AMT/B/4. In [39]. URL:

http://www.turingarchive.org/browse.php/B/4

[36] Turing, A. M. (1951) Transcript copy of letter from AMT to Professor J.Z. Young, F.R.S., 8 February. AMT/K/1/78. In [39]. URL:

http://www.turingarchive.org/browse.php/K/1/78

[37] Turing, A. M. (1951) Can digital computers think? Typescript with annotations of a talk broadcast on BBC Third Programme, 15 May. AMT/B/5. In [39]. URL:

http://www.turingarchive.org/browse.php/B/5

[38] Turing, A. M. (1952) The chemical basis of morphogenesis. Philosophical Transactions of the Royal Society of London, 237(641), pp. 37-72. DOI:

https://doi.org/10.1098/rstb.1952.0012

[39] Turing Digital Archive (n.d.) The Turing Digital Archive. Archive Centre, King's College, Cambridge, UK. URL: http://www.turingarchive.org

[40] Turing, S. (2012) Alan M. Turing. Cambridge University Press.

[41] Verdelot, P. (2006) Madrigals for a Tudor King. Obsidian Records, AllMusic. URL: https://www.allmusic.com/performance/italia-mia-madrigal-mq0001310520

[42] Verdelot, P., et al. (1973) Da Vinci - Music from His Time. Spotify. URL: https://open.spotify.com/album/5WvjCrYXZQzhV1rvezFiVW 
[43] VisitUffizi (2019) Water as Microscope of Nature. Leonardo da Vinci's Codex Leicester, 30 October - 20 January. Uffizi Gallery Museum in Florence Guide. URL: https://www.visituffizi.org/museum/exhibitions/

[44] Vive Arts (2019) Mona Lisa: Beyond the Glass. Art \& Photography, Vive Arts. The Musée du Louvre, Paris, France, 24 October 2019 - 24 February 2020. URL:

https://arts.vive.com/us/articles/projects/art-photography/mona_lisa_beyond_the_glass/

[45] Walsh, N. (2019) Celebrating the 500th Anniversary of Leonardo's death. The New York Times, 12 February. URL: https://www.nytimes.com/2019/02/12/travel/leonardo-davinci-travel-tours-museums.html

[46] WikiArt (n.d.). Leonardo da Vinci. WikiArt Visual Art Encyclopedia. URL: https://www.wikiart.org/en/leonardo-da-vinci

[47] Weinel, J., Bowen, J. P., Diprose, G., and Lambert, N. (eds.) (2019) EVA London 2019: Electronic Visualisation and the Arts. BCS, Electronic Workshops in Computing (eWiC). ScienceOpen. DOI: https://doi.org/10.14236/ewic/EVA2019.0

[48] Weinel, J., Bowen, J. P., Diprose, G., and Lambert, N. (eds.) (2020) EVA London 2020: Electronic Visualisation and the Arts. BCS, Electronic Workshops in Computing (eWiC). ScienceOpen. DOI: https://doi.org/10.14236/ewic/EVA2020.0

[49] Veltman, K. H. and Keele, K. D. (1986) Studies on Leonardo da Vinci I: Linear perspective and the visual dimensions of science and art. Deutscher Kunstverlag.

[50] Zöllner, F. (2003) Leonardo da Vinci: Complete Paintings and Drawings. Taschen. 